\title{
Cost-Effectiveness of Coronary and Peripheral Artery Disease Antithrombotic Treatments in Finland
}

\author{
Erkki Soini (D) - Outi Virtanen · Saku Väätäinen · Jean-Baptiste Briere (D) • \\ Kevin Bowrin · Aurelie Millier
}

Received: April 14, 2020 / Published online: June 9, 2020

(C) The Author(s) 2020

\begin{abstract}
Introduction: Currently, 15-20\% of individuals with coronary artery disease (chronic coronary syndrome [CCS]) or peripheral artery disease (PAD) receiving routine treatment experience cardiovascular events (CVEs) within 3-4 years. Using PICOSTEPS (Patients-Intervention-Comparators-Outcomes-Setting-Time-Effects-Perspective-Sensitivity analysis) reporting, we evaluated the cost-effectiveness of recently approved rivaroxaban $2.5 \mathrm{mg}$ twice daily in combination with acetylsalicylic acid $100 \mathrm{mg}$
\end{abstract}

Digital Features To view digital features for this article go to https://doi.org/10.6084/m9.figshare.12377645.

Electronic supplementary material The online version of this article (https://doi.org/10.1007/s12325020-01398-8) contains supplementary material, which is available to authorized users.

E. Soini $(\varangle) \cdot S$. Väätäinen

ESiOR Oy, Kuopio, Finland

e-mail: erkki.soini@esior.fi

URL: http://www.linkedin.com/in/erkkisoini/

O. Virtanen

Bayer Oy, Espoo, Finland

J.-B. Briere

Bayer AG, Berlin, Germany

K. Bowrin

Bayer Plc, Reading, UK

A. Millier

Creativ-Ceutical, Paris, France daily (RIV + ASA) for the prevention of CVEs among Finns with CCS or symptomatic PAD.

Methods: Myocardial infarction, ischemic stroke, intracranial hemorrhage, acute limb ischemia, amputations, major extracranial bleeding, venous thromboembolism, and cardiovascular deaths were modeled in a Markov model examining a cohort of patients with CCS or symptomatic PAD. Relative effects of the intervention (RIV + ASA) and comparator (ASA) were based on the COMPASS trial. The primary outcome was 3\%/year discounted incremental cost-effectiveness ratio (ICER), defined as cost (2019 euros) per quality-adjusted life year (QALY) gained in the Finnish setting over a lifetime horizon. In addition to nonfatal and fatal CVEs, the effects factored Finnish nonCVE mortality, quality of life, and direct costs from a public payer perspective. Disaggregated costs and QALYs, costs per life year gained (LYG), and ischemic strokes avoided, net monetary benefit (NMB), expected value of perfect information (EVPI), economic value-added (EVA), cost-effectiveness table, and acceptability frontier were examined. Probabilistic and deterministic sensitivity analyses were conducted.

Results: In the deterministic comparison with ASA over a lifetime horizon, RIV + ASA resulted in a benefit of 0.404 QALYs and 0.474 LYGs for an additional cost of $€ 3241$, resulting in an ICER of $€ 8031 / \mathrm{QALY}$. The probabilistic ICER was $€ 4313 /$ QALY (EVPI €1829/patient). RIV + ASA 
had positive NMB (€8791/patient), low EVPI (€88/patient), high EVA (€8703/patient), and 91\% probability of cost-effectiveness using the willingness-to-pay of $€ 25,254 / \mathrm{QALY}$. The primary result was conservative and robust for RIV + ASA.

Conclusion: RIV + ASA was a cost-effective treatment alternative compared with ASA in patients with CCS or symptomatic PAD in Finland.

\section{PLAIN LANGUAGE SUMMARY}

Finland lacks published evidence on the costeffectiveness of approved interventions for the prevention of cardiovascular events among individuals with chronic coronary syndrome (stable coronary artery disease) or symptomatic peripheral artery disease at risk of cardiovascular complications. Rivaroxaban $2.5 \mathrm{mg}$ twice daily plus acetylsalicylic acid $100 \mathrm{mg}$ once daily is indicated and reimbursed in Finland for the prevention of cardiovascular events for patients with stable coronary artery disease or symptomatic peripheral artery disease. We assessed the effectiveness and costs of treatment with rivaroxaban plus acetylsalicylic acid in comparison with treatment with acetylsalicylic acid. That is, we examined whether rivaroxaban is cost-effective when prescribed in combination with acetylsalicylic acid.

Cardiovascular events with their associated costs and impact on quality of life were modeled over the lifetime of patients. The main effectiveness outcome was quality-adjusted life years (modeled survival multiplied by the expected quality of life), and costs included those relevant to the Finnish public payer in 2019. Extensive sensitivity analyses were carried out to evaluate the impacts of different model inputs and rationale.

Rivaroxaban plus acetylsalicylic acid had high probability of being cost-effective, compared with acetylsalicylic acid. By valuing quality-of-life benefit with a plausible willingness-to-pay, net cost savings of $€ 8791$ per patient could be gained or economic value added by $€ 8703$ per patient if rivaroxaban was used.

Keywords: Acetylsalicylic acid; Cardiovascular disease; Chronic coronary syndrome; Coronary artery disease; Cost-benefit analysis; Costeffectiveness analysis; Economic evaluation; Peripheral artery disease; Rivaroxaban; Symptomatic

\section{Key Summary Points}

Why carry out this study?

Many patients with chronic coronary syndrome or symptomatic peripheral artery disease have a high risk of ischemic events.

We studied whether intensified antithrombosis with rivaroxaban $2.5 \mathrm{mg}$ twice daily in addition to acetylsalicylic acid $100 \mathrm{mg}$ once daily would be costeffective compared to antithrombotic treatment with acetylsalicylic acid alone.

\section{What was learned from the study?}

In this modeled study, rivaroxaban was cost-effective and produced added value when used in addition to acetylsalicylic acid irrespective of the analyzed patient subgroup.

With the assumed willingness-to-pay threshold derived from the UK, rivaroxaban had a $91 \%$ probability of being cost-effective, and produced a high net monetary benefit of $€ 8791$ with low opportunity cost of $€ 88$ per patient.

In future studies, society should be willing to examine large-scale issues such as chronic cardiovascular diseases to assess and avoid their direct, indirect, and opportunity costs. 


\section{INTRODUCTION}

Cardiovascular diseases (CVDs) comprise diseases of the heart and blood vessels, including coronary heart disease (CHD), coronary artery disease (CAD), peripheral artery disease (PAD), and several other conditions that increase the risk of cardiovascular events (CVEs) [1]. CHD includes angina pectoris, myocardial infarction (MI), or silent myocardial ischemia. CHD originates from $\mathrm{CAD}$, which is a pathologic process affecting the coronary arteries due to atherosclerosis [1, 2]. PAD is also caused by atherosclerosis [3].

The prevalence of CVD increases with age and was 3\%, 6\%, 13\%, and 27\% among Finns aged 50-59, 60-69, 70-79, and 80 years or older, respectively [4]. Consequently, CVD and CVEs are the leading causes of death in developed countries with aging populations. For instance, CVD accounts for $36 \%$ of all deaths among Finns aged 35 years or older [5,6]. Overall, CHD mortality results from CAD [1]. Among patients with symptomatic $\mathrm{PAD}, \mathrm{CAD}$, end-stage renal disease, and high age increase cardiovascular (CV) mortality [7].

Irrespective of the decline in the risk of CHD death among working-age Finns [8], patients without cardiac operation or undergoing coronary angiography have poor patient-reported outcomes [9]. On the basis of Finnish real-world evidence (RWE), patients with CVD were found to have impaired health-related quality of life (HRQoL) in a national survey [10], local specialist care [9], and primary care [11] settings. However, CVD is still underdiagnosed: Korhonen et al. [12] found that among a Finnish cohort of apparently healthy individuals with increased CV risk, 33\% had undiagnosed hypertension, diabetes, PAD, or renal insufficiency.

Lastly, CVEs such as stroke or MI are associated with significant specialized care costs [13-16] and HRQoL loss [15, 16]. Overall, CVDs are the largest contributor to primary and specialized care costs among unselected patients in primary care settings [17].

Treatments that reduce the risk of CVEs are the cornerstone of CVD treatment [3, 18, 19].
However, $15-20 \%$ of conventionally treated individuals in secondary prevention experience a CVE within 3-4 years [20]. Acetylsalicylic acid $100 \mathrm{mg}$ daily (ASA, low dose) has long been the mainstay antithrombotic treatment for CAD or $\operatorname{PAD}[3,19]$. However, rivaroxaban $2.5 \mathrm{mg}$ twice daily (RIV) plus ASA (RIV + ASA) once daily has demonstrated its clinical value in the COMPASS trial for stable CAD or symptomatic PAD populations at risk of CVE, showing superior efficacy compared with ASA [20-29].

For patients with stable CAD, the combination of RIV and ASA has been recommended by the recent European Society of Cardiology (ESC) clinical practice guidelines for the management of chronic coronary syndromes (CCS). Since the clinical presentations of CAD can be categorized as either acute coronary syndrome or CCS, stable CAD was replaced by CCS in the ESC guidelines [30]. For simplicity, CCS is used in this study to reflect the stable CAD [30] (i.e., chronic CAD [31]) population. Full health economic evaluation of CCS or symptomatic PAD in Finland has not been published. Thus, the present study examines the cost-effectiveness of RIV + ASA versus ASA for the prevention of major adverse CVEs in patients with CCS or symptomatic PAD.

\section{METHODS}

The present modeling was part of the application of reasonable wholesale price and reimbursement for RIV in Finland and is in line with the official Finnish health economic evaluation guideline [32]. Following the guideline [32] and Finnish experience a Patients-InterventionComparator-Outcome-Setting-Time-Effects-Perspective-Sensitivity analysis approach (PICOSTEPS [33-35]) was implemented. The PICOSTEPS analysis is summarized in Table 1.

\section{Patients}

The modeled patient cohort included adult patients with CCS or symptomatic PAD. The COMPASS trial population baseline characteristics (Table 1) and treatments were similar to those of the typical Finnish CCS or PAD patient 
Table 1 Health economic evaluation in the PICOSTEPS framework

\begin{tabular}{|c|c|}
\hline Component & Content \\
\hline P: Patients & $\begin{array}{l}\text { Finns with CCS and/or symptomatic PAD and at risk of CVEs (CCS or PAD) } \\
\text { Based on the COMPASS trial, CCS or PAD: age } 68.2 \text { years (SD } 7.9 \text { years), } N=27,395,78.0 \% \text { male } \\
\text { Respective subgroups from the COMPASS trial: CCS }(68.3[7.8] ; 24,824 ; 79.7 \%), P A D(67.8[8.5] \text {; } \\
\quad 7470 ; 71.8 \%) \text {, CCS and PAD (68.1 [8.2]; 4906; 77.1\%), CCS with HF (65.5 [9.0]; 5714; 77.3\%), } \\
\text { CCS with CKD (71.4 [7.3]; 5561; 70.8\%) }\end{array}$ \\
\hline I: Intervention & Lifelong RIV + ASA \\
\hline C: Comparator & Lifelong ASA \\
\hline O: Outcomes & $\begin{array}{l}\text { Primary: Deterministic ICER defined as additional costs (euros)/QALY gained } \\
\text { Secondary: ICER defined as cost/LYG, cost/IS avoided, cost/year without CVE, total and disaggregated } \\
\text { costs and QALYs, and CVEs } \\
\text { Tertiary: Probabilistic ICER, NMB, EVPI, EVA, and cost-effectiveness acceptability frontier }\end{array}$ \\
\hline S: Setting & Finland. ICE analysis based on Markov model with EFHS, MCVEs, OE, and mortality \\
\hline T: Time & $\begin{array}{l}\text { Lifetime horizon (max age } 100 \text { years), } 2019 \text { base year with year } 2019 \text { expected drug and other costs, } \\
3 \text { months modeling cycle. } 3 \% \text { discounting/annum }\end{array}$ \\
\hline E: Effects & $\begin{array}{l}\text { ASA transition probabilities for MCVE, OE, and CV-adjusted Finnish general population mortality, } \\
\text { HR for RIV + ASA, EQ-5D-3L HRQoL from the COMPASS trial adjusted to Finland, and } \\
\text { Finnish RWE of costs }\end{array}$ \\
\hline P: Perspective & $\begin{array}{l}\text { Finnish public payer perspective, i.e., patient co-payments, travelling and indirect costs (absenteeism, } \\
\text { presenteeism, sickness allowances, pensions, education, unemployment, household chores, taxes, and } \\
\text { other income transfers) ignored }\end{array}$ \\
\hline
\end{tabular}


Table 1 continued

\begin{tabular}{|c|c|}
\hline Component & Content \\
\hline \multirow{19}{*}{$\begin{array}{l}\text { S: Sensitivity } \\
\text { analyses }\end{array}$} & Scenario analyses including: \\
\hline & $\begin{array}{l}\text { Patients: Subgroups of patients. For robust modeling, the HRs for RIV + ASA versus ASA were the } \\
\text { same as in the base case }\end{array}$ \\
\hline & Time: Time horizon: 15 years; discounting: 0\%, 5\%; cost year: 2020, 2021 \\
\hline & Effects: \\
\hline & $\begin{array}{l}\text { Event and death transition probabilities with zero probability after the first event imputed (EFHS } \\
\text { figures); and zero event probabilities from EFHS to a second event and zero probabilities for death } \\
\text { imputed }(0.00001)\end{array}$ \\
\hline & $\begin{array}{l}\text { Discontinuation rate of } 0.029 / 3 \text {-month cycle for RIV applied for the first } 4 \text { years and the treatment } \\
\text { costs for patients discontinuing RIV + ASA modeled as equal to ASA treatment costs }\end{array}$ \\
\hline & $\begin{array}{l}\text { The RIV discontinuation rate used for the full model duration and the transition and event } \\
\text { probabilities and treatment costs after discontinuing RIV + ASA modeled to be equal to ASA }\end{array}$ \\
\hline & The most recent MCVE cost applied for MCVEs \\
\hline & Additive MCVE costs applied for MCVEs \\
\hline & HRQoL based on the most recent MCVE \\
\hline & Multiplicativity of MCVE HRQoL \\
\hline & HRQoL from ATLAS with age adjustment \\
\hline & HRQoL from literature \\
\hline & Deterministic sensitivity analysis \\
\hline & Probabilistic sensitivity analysis distributions \\
\hline & $\begin{array}{l}\text { Patients: Beta gender; normal baseline age; lognormal age-dependent CVE risk and age-dependent CV } \\
\text { death risk }\end{array}$ \\
\hline & Intervention: lognormal CVE HRs and CV death HRs \\
\hline & $\begin{array}{l}\text { Comparator: Beta EFHS, MCVE risks, OE risks, mortalities and proportion of IS deaths among } \\
\text { stroke patients; lognormal OE durations }\end{array}$ \\
\hline & Effects: Gamma for costs; Beta for HRQoL values and disutilities \\
\hline
\end{tabular}

$A S A$ acetylsalicylic acid $100 \mathrm{mg}$ once daily, $C C S$ chronic coronary syndrome, $C K D$ chronic kidney disease, $C V E$ cardiovascular event, $E F H S$ event-free health state, $E V A$ economic value-added, $E V P I$ expected value of perfect information, $H F$ heart failure, $H R$ hazard ratio, $H R Q o L$ health-related quality of life, ICE incremental cost-effectiveness, ICER incremental cost-effectiveness ratio, $I S$ ischemic stroke, $L Y G$ life years gained, $M C V E$ main cardiovascular event, $N M B$ net monetary benefit, $O E$ other event, $P A D$ peripheral artery disease, $Q A L Y$ quality-adjusted life years, $R I V$ rivaroxaban $2.5 \mathrm{mg}$ twice daily, $R W E$ real-world evidence, $S D$ standard deviation 
population $[3,9,19]$. These were also generally in line with the international REACH $[36,37]$ and Polish TERCET-CAD registries [38].

Results based on different patient characteristics (Table 1) were explored from the subgroup analyses of COMPASS (see Table S1 in the electronic supplementary material). The patient characteristics impacted mortality and HRQoL in the analysis. In addition, the patient subgroups impacted the transition probabilities and HRQoL.

The modeling was based on previously conducted studies and did not include any new studies with human participants or animals performed by any of the authors and was not registered with any clinical trial database.

\section{Intervention and Comparator}

The examined intervention, RIV + ASA, was compared with the recommended standard of care comparator, ASA $[3,15,18,19,30$, 35, 39-48].

RIV is the only non-vitamin $\mathrm{K}$ antagonist oral anticoagulant indicated alongside ASA for the treatment of stable CAD or symptomatic PAD. RIV has a place in the European recommendations [30, 39] and has recently been recommended by the United Kingdom National Institute for Health and Care Excellence (UK NICE) [49].

\section{Outcomes}

The primary outcome of the present study was the deterministic incremental cost-effectiveness ratio (ICER):

$$
\begin{aligned}
& \text { ICER }_{\text {RIV2.5+ASA100 }}
\end{aligned}
$$

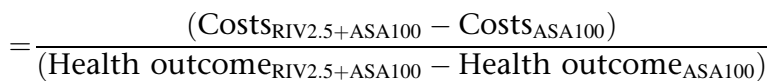

The study examined incremental costs per additional quality-adjusted life year (cost/ QALY), in line with the Finnish health economic evaluation [32] and Health Technology Assessment [50], as well as the UK NICE guidelines [51].
The study also examined the incremental costs per additional life year (LY) gained (cost/ LYG), the cost per year without CVE (cost/CVE year avoided), the costs per avoided ischemic stroke (IS; the most important CVE outcome due to its high costs and HRQoL effects, cost/IS avoided), the number of different events and disaggregated costs, and QALYs as secondary outcomes.

Lastly, the probabilistic ICER, the net monetary benefit (NMB), and the economic value added (EVA) were included and based on the assumed willingness-to-pay threshold (WTP):

$$
\begin{aligned}
& \mathrm{NMB}_{\mathrm{RIV} 2.5}=\mathrm{WTP}_{\mathrm{RIV} 2.5} *\left(\mathrm{QALYs}_{\mathrm{RIV} 2.5+\mathrm{ASA} 100}\right. \\
& \left.-\mathrm{QALYs}_{\mathrm{ASA} 100}\right)-\left(\text { Costs }_{\mathrm{RIV} 2.5+\mathrm{ASA} 100}-\text { Costs }_{\mathrm{ASA} 100}\right),
\end{aligned}
$$

and the expected value of perfect information (EVPI). The last outcomes were important in the assessment of joint uncertainty related to the modeled parameters and its potential consequences.

\section{Setting}

CCS and PAD are chronic conditions associated with fatal and nonfatal events. The costs and QALYs depend both on the occurrence and timing of these events over time, leading to a need for modeling in the health economic evaluation. Markov state-transition modeling (Fig. 1) was done using Microsoft Excel including Visual Basic for Application. Markov models are a commonly used approach, especially for chronic diseases, which assume that a cohort can be classified into a finite number of mutually exclusive health states defined by disease or treatment parameters. Markov trace (i.e., a patient trajectory) is represented as a series of memoryless (i.e., dependent only on the current health state) transitions from one health state to another.

Each health state has a specific HRQoL weight, a value from zero (death) to one (full health), as well as costs. Health state-specific costs and health benefits are aggregated at the end of the modeled time horizon.

The patients first enter the Markov model in the event-free health (EFH) state. Over the 


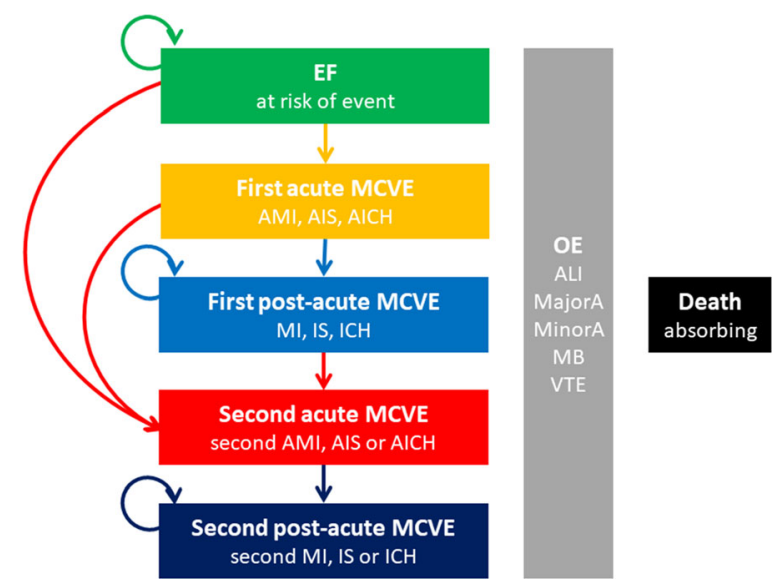

Fig. 1 Simplified presentation of Markov model. OE or death may happen from any state. AICH acute intracranial hemorrhage, AIS acute ischemic stroke, ALI acute limb ischemia, AMI acute myocardial infarction, EF event-free, ICH intracranial hemorrhage, IS ischemic stroke, MajorA major amputation, MB major nonfatal extracranial bleeding, MCVE main cardiovascular event, MI myocardial infarction, MinorA minor amputation, OE other event, VTE venous thromboembolism

modeled time horizon, the patients could remain in the EFH state or experience a first/ second main CVE (MI, IS, or intracranial hemorrhage [ICH]), experience two main CVEs during the model cycle, or die. The main CVEs impacted the subsequent main CVE risks and survival. Each main CVE was divided into acute and post-acute phases. The patients moved directly to the acute second main CVE from the EFH state if the patient experienced two CVEs within one cycle.

The inclusion of the second main CVE was done to reflect the clinical reality and to overcome the memoryless feature of the Markov model. However, as a result of the low proportion of patients with three or more main CVEs, a third main CVE was not modeled. This was conservative for RIV + ASA, because the potential benefit was underestimated as a result of the 4-year follow-up.

In addition to main CVEs, the patients in the model could experience other events, including acute limb ischemia (ALI), amputations, major nonfatal extracranial bleeding (MB), or venous thromboembolism (VTE). The other events impacted HRQoL and costs. Because fatal bleeding events and ICH were already considered as part of main CVEs, MB was defined as major nonfatal extracranial bleeding to avoid double counting. All modeled CVEs, defined in Eikelboom et al. [21], were based on their significance or clinical relevance. The impact of treatment sequencing was excluded for simplicity.

\section{Time}

The cycle length of the model is a compromise between accuracy and simplicity. A 3-month cycle length was used in agreement with clinical expert opinion, identified in previously published models in the therapeutic area and available cost information. A half-cycle correction using the number of patients in the middle of the cycle was used to decrease the risk of over/underestimating and to fix the most probable mean time at risk of an event during each cycle.

Accounting for the fact that CVE risks and outcomes were relevant for the duration of a patient's life, modeling lifetime up to a maximum of 100 years of age was considered adequate to capture the relevant costs and health outcomes associated with the compared treatments in Finland $[32,50])$ and other settings [51-55].

Because the time horizon exceeded 1 year, the analyses were conducted with a $3 \%$ annual discounting rate for costs and effectiveness as well as without discounting in a sensitivity analysis [32, 50]. Analytical base year was set at 2019.

\section{Effects}

\section{Transitions}

A two-step approach was used in the estimation of transition probabilities. First, the mean transition probabilities for ASA were calculated from the COMPASS trial for the first 4 years, including the subtraction of background mortality. To extrapolate ASA transition 
probabilities beyond the first 4 years in an aging cohort, age-dependent hazard ratios (HRs) from the large international REACH registry were applied for the next main CVE and death to main CVE [36]. Potential effects of ASA to the extrapolated transitions from the REACH were not considered [56].

Second, the transition probabilities for RIV + ASA were calculated using HRs sourced from the COMPASS trial population, which were applied to the ASA transition probabilities. The proportional hazards assumption of HRs and the stability of treatment effect was confirmed by parallelism of the plot of negative log of Kaplan-Meier (KM) estimates of survival function versus the log of time. A smoother plot of scaled Schoenfeld residuals indicated no increase or decrease in relative risk during the COMPASS trial, and the log-transformed time-treatment interaction term was nonsignificant when included in the Cox model.

The background mortality of the general population was considered and based on official Finnish statistics. On the basis of the official statistics, an average per cycle death probability was computed, accounting for the modeled average age and baseline gender distribution. To avoid double counting, CV deaths [6] were removed from the background mortality [5]. Survival was truncated to 100 years of age for conservative estimation and due to lack of mortality data. Adverse events (other than $\mathrm{MB}$ ) were not considered because there were no clinically relevant differences between RIV + ASA and ASA in the COMPASS trial [21].

\section{Health-Related Quality of Life}

Multivariate regression analyses were conducted for the EQ-5D measured during the COMPASS trial. The HRQoL in health states and disutilities (HRQoL decrements) associated with events were based on the results of the generalized estimating equation (Table 2 ). The results of the repeated measure mixed model are presented to assess the robustness of generalized estimating equation results (see Table $S 1$ in the electronic supplementary material). A multiplier, calculated as the HRQoL ratio between the CCS or PAD and the subgroup populations, was used to derive the subgroup-specific HRQoL weights for each health state (Table 2).

The HRQoL score in EFH state was 0.835 in the COMPASS trial, which was considered reasonable for Finland. On the basis of Finnish RWE [10] and the COMPASS trial patient characteristics [21], the average EQ-5D-3L score was estimated to be approximately 0.839 in the Finnish population. Because HRQoL generally decreases with age [10] and there was an estimated 0.004 difference in the EFH state HRQoL between the COMPASS trial patients and a similar Finnish population, adjustment to the local setting was done using age group-specific multipliers applied to the COMPASS-based HRQoL values (Table 2).

As expected, the COMPASS trial did not include enough data for the estimation of a second CVE HRQoL. The HRQoL associated with the second main CVE was determined as the lower HRQoL that a patient with two main CVEs was modeled to experience. The base-case analysis did not consider that both main CVEs may affect HRQoL independently and additively, which is conservative.

\section{Costs}

Lifetime treatment duration with a constant dose was consistent with drug labelling, and thus, treatment discontinuation was not modeled. Although not realistic, because patients did discontinue in COMPASS, this was a conservative approach for RIV due to RIV costs being cumulated if patients were alive, whereas efficacy was derived from the intention-to-treat population. Expected pack sizes and costs for RIV and ASA were predicted for years 2019-2021 on the basis of Finnish RWE and market statistics. The drug costs were official list prices in July 2019 (Table 3).

To follow the costing years used for the drugs, the healthcare part of the Finnish Communal Expenses Index $[57,58]$ from the years 2000 to 2018 was used to predict year 2019-2021 index values:

$$
\begin{aligned}
\text { Index }= & -0.105 * \text { year }^{2}+5.044 * \text { year } \\
& +96.2270
\end{aligned}
$$

where year is $19-21$. 
Table 2 Health-related quality of life, by subgroup and health state (underlined values were used to inform the model in the base-case analysis)

\begin{tabular}{|c|c|c|c|c|c|c|c|c|}
\hline \multicolumn{2}{|c|}{ Generalized estimating equation } & \multirow{2}{*}{$\frac{\text { EFHS }}{\text { MCVE disutility }^{\mathrm{b}}}$} & \multirow{2}{*}{$\frac{\mathbf{A M I}^{\mathbf{a}}}{-0.051}$} & \multirow{2}{*}{$\frac{\text { MI }}{-0.028}$} & \multirow{2}{*}{$\frac{\mathbf{A I S}^{\mathbf{a}}}{-0.188}$} & \multirow{2}{*}{$\frac{\text { IS }}{-0.092}$} & \multirow{2}{*}{$\frac{\mathbf{A I C H}^{\mathbf{a}}}{-0.133}$} & \multirow{2}{*}{$\frac{\text { ICH }}{-0.080}$} \\
\hline Population & & & & & & & & \\
\hline CCS or PAD & Multiplier $^{\mathrm{c}}$ & 0.835 & 0.784 & 0.807 & 0.647 & 0.743 & 0.702 & 0.755 \\
\hline CCS & 1.0084 & 0.842 & 0.791 & 0.814 & 0.652 & 0.749 & 0.708 & 0.761 \\
\hline PAD & 0.9425 & 0.787 & 0.739 & 0.761 & 0.610 & 0.700 & 0.662 & 0.712 \\
\hline $\mathrm{CCS}$ and PAD & 0.9533 & 0.796 & 0.747 & 0.769 & 0.617 & 0.708 & 0.669 & 0.720 \\
\hline CCS with HF & 0.9581 & 0.800 & 0.751 & 0.773 & 0.620 & 0.712 & 0.673 & 0.723 \\
\hline CCS with CKD & 0.9737 & 0.813 & 0.763 & 0.786 & 0.630 & 0.723 & 0.684 & 0.735 \\
\hline Prior MI and CKD & 0.9725 & 0.812 & 0.762 & 0.785 & 0.629 & 0.723 & 0.683 & 0.734 \\
\hline Polyvascular disease & 0.9485 & 0.792 & 0.744 & 0.765 & 0.614 & 0.705 & 0.666 & 0.716 \\
\hline CCS or PAD, prior stroke & 0.8922 & 0.745 & 0.699 & 0.720 & 0.577 & 0.663 & 0.626 & 0.674 \\
\hline $\mathrm{CCS}$ or $\mathrm{PAD}$, diabetes & 0.9784 & 0.817 & 0.767 & 0.790 & 0.633 & 0.727 & 0.687 & 0.739 \\
\hline \multicolumn{3}{|c|}{ Adjustment of MCVE HRQoL to the Finnish setting } & \multicolumn{6}{|c|}{ Age, years } \\
\hline Characteristics & Full loss & Proportion & $<44$ & $45-54$ & $55-64$ & $65-74$ & $75-84$ & $\geq 85$ \\
\hline HRQoL, women & - & - & 0.885 & 0.885 & 0.885 & 0.885 & 0.885 & 0.885 \\
\hline Age loss & - & - & - & -0.022 & -0.052 & -0.043 & -0.077 & -0.200 \\
\hline Income, average & - & - & 0.025 & 0.025 & 0.025 & 0.025 & 0.025 & 0.025 \\
\hline Education, middle & - & - & 0.011 & 0.011 & 0.011 & 0.011 & 0.011 & 0.011 \\
\hline Men, gain & 0.011 & $78.0 \%$ & 0.009 & 0.009 & 0.009 & 0.009 & 0.009 & 0.009 \\
\hline CHD, loss & -0.011 & $90.6 \%$ & -0.010 & -0.010 & -0.010 & -0.010 & -0.010 & -0.010 \\
\hline Hypertension, loss & -0.012 & $75.3 \%$ & -0.009 & -0.009 & -0.009 & -0.009 & -0.009 & -0.009 \\
\hline Diabetes, loss & -0.041 & $37.7 \%$ & -0.015 & -0.015 & -0.015 & -0.015 & -0.015 & -0.015 \\
\hline Previous stroke, loss & -0.090 & $3.8 \%$ & -0.003 & -0.003 & -0.003 & -0.003 & -0.003 & -0.003 \\
\hline HF, expected loss & -0.044 & $21.5 \%$ & -0.009 & -0.009 & -0.009 & -0.009 & -0.009 & -0.009 \\
\hline HRQoL, expected & & & 0.882 & 0.860 & 0.830 & 0.839 & 0.805 & 0.682 \\
\hline HRQoL multiplier ${ }^{\mathrm{d}}$ & & & 1.057 & 1.030 & 0.994 & 1.005 & 0.964 & 0.817 \\
\hline
\end{tabular}


Table 2 continued

\begin{tabular}{llllll}
\hline OEs & & & & \\
\hline Event & ALI & MinorA $^{\mathbf{e}}$ & MajorA $^{\mathbf{e}}$ & $\mathbf{M B}^{\mathbf{f}}$ & VTE \\
\hline $\begin{array}{l}\text { HRQoL } \\
\text { loss }\end{array}$ & -0.157 & -0.100 & -0.175 & -0.019 & -0.111 \\
\hline
\end{tabular}

$A I C H$ acute intracerebral hemorrhage, $A I S$ acute ischemic stroke, $A L I$ acute limb ischemia, $A M I$ acute myocardial infarction, $C C S$ chronic coronary syndrome, $C H D$ congestive heart disease, $C K D$ chronic kidney disease, $E F H S$ event-free health state, $H F$ heart failure, HRQOL health-related quality of life, ICH intracerebral hemorrhage, IS ischemic stroke, ISTH International Society on Thrombosis and Haemostasis, MajorA major amputation, $M B$ major bleeding, MCVE main cardiovascular event, $M I$ myocardial infarction, Minor $A$ minor amputation, $O E$ other event, $P A D$ peripheral artery disease, $V T E$ venous thromboembolism

${ }^{a}$ Acute indicates the first 3 months after the index event

b Disutilities were added to subgroup EFHS HRQoL score to obtain utility weights for each health state

${ }^{c}$ Ratio between the CCS or PAD population, and the subgroup of interest; used to derive the HRQoL for the health states

d Calculated on the basis of expected HRQoL gains and losses based on the COMPASS patients characteristics [21] and Finnish HRQoL results [10]: average $(0.885)+$ specific loss of age group $(-0.022$ for $45-54,-0.052$ for $55-64,-0.043$ for $65-74,-0.077$ for $75-84,-0.200$ for $\geq 85)+$ average income $(0.025)+$ middle education $(0.011)+$ proportion of men $(0.780) \times$ gain of men $(0.011)+$ proportion with CHD $(0.906) \times$ loss with CHD $(-0.011)+$ proportion with hypertension $(0.753) \times$ loss with hypertension $(-0.012)+$ proportion with diabetes $(0.377) \times$ loss with diabetes $(-0.041)+$ proportion with previous stroke $(0.038) \times$ loss with stroke $(-0.090)+$ proportion with $\mathrm{HF}(0.215) \times$ loss with stroke $(-0.044)$

${ }^{\mathrm{e}}$ Lifelong duration

${ }^{\mathrm{f}}$ Major bleeding defined in accordance with modified ISTH criteria

Following the approach set out in Heeg et al. [59], and other sources, acute and post-acute CVEs, as well as those associated with fatal events, were separated (Table 3). Primary care resource use and costs associated with CVEs were based on the Finnish RWE from the Pirkanmaa area [17] and valued using the official unit costs [60]. Specialized care costs were based on RWE from the Finnish treatment discharge register covering all relevant Finns $[15,16]$. IS and ICH costs applied severity distributions from the COMPASS trial [27]. The second main CVE costs were modeled conservatively as the maximum costs of acute and post-acute health states of a patient with two events (no additivity assumed, i.e., the cost of the second main CVE was not added to the cost of the first main CVE).

$\mathrm{CV}$-related mortality costs were modeled on the basis of the Finnish RWE [16]. Non-CV deaths were modeled not to incur any costs, which was conservative for RIV + ASA.

\section{Perspective}

Direct costing with a public payer perspective was applied, which included drug, primary and secondary care visits, and hospitalization costs (Table 1). The interpretation of ICER was complicated by the lack of official Finnish WTPs $[61,62]$, i.e., how much additional cost/QALY is acceptable. In Finland, the UK thresholds in euros have been applied as WTPs in previous cost-effectiveness analysis [35].

Here, WTP/QALY was set conservatively to $£ 20,000$ based on the most plausible threshold set by NICE [51] and converted to the Finnish euro using 2018 purchasing power parities [63], resulting in a WTP of $€ 25,254 / \mathrm{QALY}$. As recommended by NICE [51], this WTP of $€ 25,254 /$ QALY was used to estimate the NMB (i.e., monetary value when valuing also QALYs in euros).

\section{Sensitivity analyses}

Deterministic scenario analyses (multiway or rationality analyses) were conducted to assess the robustness of the modeling approach in 
Table 3 Costs

\begin{tabular}{|c|c|c|c|c|c|c|c|c|c|c|c|c|}
\hline \multirow{2}{*}{\multicolumn{3}{|c|}{$\begin{array}{l}\text { Drug costs } \\
\text { Brand }\end{array}$}} & \multirow[b]{2}{*}{$\overline{\text { Pack size }}$} & \multicolumn{6}{|c|}{$\begin{array}{l}\text { Retail }(€) \text { prices and treatment cost per } \\
\text { day }\end{array}$} & \multicolumn{3}{|c|}{$\begin{array}{l}\text { Market share and } \\
\text { associated costs for the } \\
\text { base year }\end{array}$} \\
\hline & & & & \multicolumn{2}{|c|}{ With VAT } & \multicolumn{2}{|c|}{ Without VAT } & \multicolumn{2}{|c|}{$\overline{\text { Cost per day }}$} & $2019^{\mathrm{a}}$ & \multirow{2}{*}{$\begin{array}{l}2020^{a} \\
10.18 \%\end{array}$} & \multirow{2}{*}{$\frac{2021^{\mathbf{a}}}{10.23 \%}$} \\
\hline \multicolumn{3}{|c|}{ ASA-Ratiopharm Tabs $100 \mathrm{mg}$} & 100 & 9.09 & & 8.26 & & 0.08 & & $9.86 \%$ & & \\
\hline \multicolumn{3}{|c|}{ Aspirin Entabscardio $100 \mathrm{mg}$} & 98 & 13.06 & & 11.8 & & 0.12 & & $0.00 \%$ & $0.00 \%$ & $0.00 \%$ \\
\hline \multicolumn{3}{|c|}{ Bartal Filmtabs Fol 100 mg } & 100 & 8.90 & & 8.09 & & 0.08 & & $0.31 \%$ & $0.19 \%$ & $0.03 \%$ \\
\hline \multicolumn{3}{|c|}{ Disperin Tabs $100 \mathrm{mg}$} & 100 & 8.49 & & 7.72 & & 0.08 & & $8.83 \%$ & $10.15 \%$ & $12.22 \%$ \\
\hline \multicolumn{3}{|c|}{ Primaspan Enterot Fol $100 \mathrm{mg}$} & 100 & 9.99 & & 9.08 & & 0.09 & & $0.00 \%$ & $0.00 \%$ & $0.00 \%$ \\
\hline \multicolumn{3}{|c|}{ Primaspan Enterotabs 100 mg } & 300 & 27.13 & & 24.6 & & 0.08 & & $3.37 \%$ & $5.13 \%$ & $9.03 \%$ \\
\hline \multicolumn{3}{|c|}{ Primaspan Enterotabs Fol $100 \mathrm{mg}$} & 100 & 9.99 & & 9.08 & & 0.09 & & $77.64 \%$ & $74.35 \%$ & $68.49 \%$ \\
\hline \multicolumn{4}{|c|}{ Per day cost $(€)$, weighted } & & & & & & & 0.09 & 0.09 & 0.09 \\
\hline \multicolumn{4}{|c|}{ Expected pack size, weighted } & & & & & & & 107 & 110 & 118 \\
\hline Brand & Pack si & & With VAT & \multicolumn{3}{|c|}{ Without VAT } & \multicolumn{2}{|c|}{ Cost per day } & \multicolumn{2}{|c|}{$2019^{b}$} & $2020^{b}$ & $2021^{b}$ \\
\hline Xarelto $2.5 \mathrm{mg}$ & 56 & & 78.95 & \multicolumn{2}{|c|}{71.77} & & 1.28 & & \multicolumn{2}{|c|}{$38.24 \%$} & $23.64 \%$ & $14.90 \%$ \\
\hline Xarelto $2.5 \mathrm{mg}$ & 168 & & 215.90 & 19 & 6.27 & & 1.17 & & 61.76 & $6 \%$ & $.00 \%$ & $0.00 \%$ \\
\hline Xarelto $2.5 \mathrm{mg}$ & 196 & & 249.02 & 22 & 6.38 & & 1.16 & & $0.00 \%$ & & $6.36 \%$ & $85.10 \%$ \\
\hline Per day cost $(€)$ & weighted & & & & & & & & 1.21 & & 18 & 1.17 \\
\hline Expected pack si & e, weighte & & & & & & & & 125 & & 63 & 175 \\
\hline Primary care co & & & & & & & & pectec & d per cycle & $e \cos t(€$ & ), base ye & $a r^{c}$ \\
\hline Ongoing care & Type & Use/c & /cycle & st $(€)$ & 2011 & & urce & 19 & & 020 & 202 & \\
\hline GP & Visit & 0.750 & & 0.00 & & {$[6$} & & .58 & & 1.14 & 91.5 & \\
\hline MI, IS, ICH, A & I, VTE, & mputa & tation, MB & Type & Use/c & ycle & Cost $(€)$, & 2011 & Source & 2019 & 2020 & 2021 \\
\hline GP & & & & Visit & 1.2115 & & 110.00 & & {$[17,60]$} & 146.32 & 147.22 & 147.93 \\
\hline PC nurse & & & & Visit & 0.6154 & & 48.00 & & {$[17,60]$} & 32.43 & 32.63 & 32.79 \\
\hline PC on-call & & & & Visit & 0.0865 & & 96.00 & & {$[17,60]$} & 9.12 & 9.17 & 9.22 \\
\hline GP & & & & Call & 0.3558 & & 26.00 & & {$[17,60]$} & 10.16 & 10.22 & 10.27 \\
\hline PC nurse & & & & Call & 0.3269 & & 12.00 & & {$[17,60]$} & 4.31 & 4.33 & 4.35 \\
\hline PC hospitalizati & & & & Days & 0.1250 & & 234.00 & & {$[17,60]$} & 32.12 & 32.31 & 32.47 \\
\hline Total & & & & & & & & & & 234.46 & 235.90 & 237.02 \\
\hline
\end{tabular}


Table 3 continued

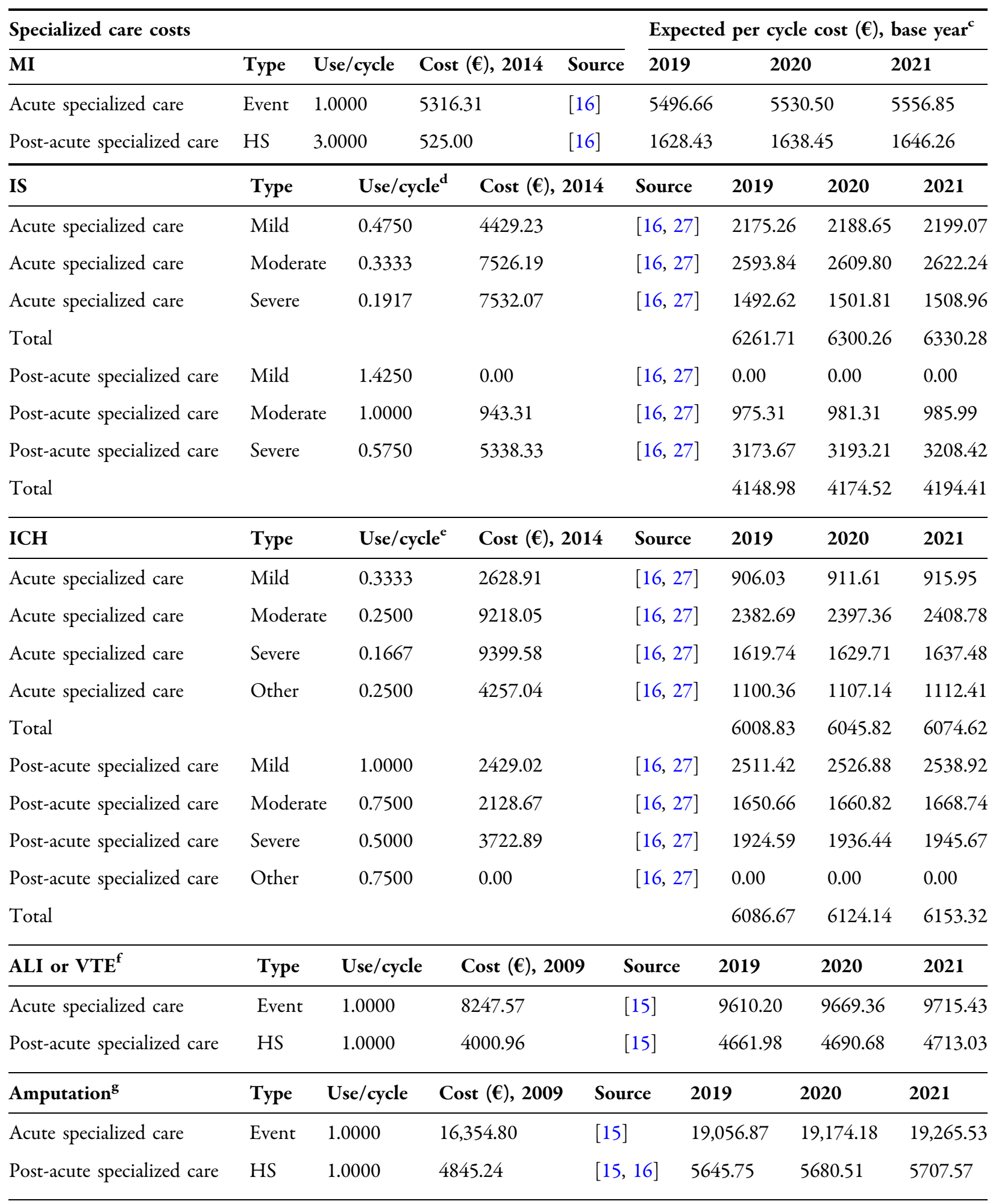


Table 3 continued

\begin{tabular}{llllllll}
\hline MB $^{\mathbf{g}}$ & Type & Use/cycle & Cost $(\boldsymbol{€}), \mathbf{2 0 1 4}$ & Source & $\mathbf{2 0 1 9}$ & $\mathbf{2 0 2 0}$ & $\mathbf{2 0 2 1}$ \\
\hline Acute specialized care & Event & 1.0000 & 3448.80 & {$[16]$} & 3565.80 & 3587.75 & 3604.84 \\
Post-acute specialized care & HS & 1.0000 & 1021.74 & {$[16]$} & 1056.40 & 1062.90 & 1067.96 \\
\hline Death due to & & & & & &
\end{tabular}

$A L I$ acute limb ischemia, $C V D$ cardiovascular disease, GP general practitioner, $H F$ heart failure, $H S$ health state, $I C H$ intracerebral hemorrhage, $I S$ ischemic stroke, $M B$ major bleeding, $M I$ myocardial infarction, $O C V D$ other cardiovascular death, $P C$ primary care, $S C E$ sudden cardiac event, $T b l$ tablet, $V A T$ value-added tax, $V T E$ venous thromboembolism

${ }^{a}$ Estimated using nonlinear predictions of Finnish sales statistics from January 2016 to April 2019

b Estimates provided by Bayer

${ }^{c}$ Estimated using nonlinear predictions of communal healthcare price index [57]

${ }^{d}$ IS severity distributions for survivors calculated from Sharma [27]

e ICH severity distributions for survivors calculated from Sharma [27]; assuming $25 \%$ of events as ICH other than hemorrhagic stroke

${ }^{\mathrm{f}}$ ALI and VTE costs were based on peripheral vascular disease costs. Costs related to amputation were not accounted for in ALI to avoid double counting, as minor and major amputations were separate events

g Costs in acute vs post-acute state were taken proportionally to AMI vs MI

${ }^{\mathrm{h}}$ Non-CV deaths were modeled not to incur costs. Costs associated with death were assigned to patient's last modeled cycle

general (Table 1). In addition, the impacts of single parameter changes were assessed with deterministic one-way sensitivity analyses covering most PICOSTEPS components, depicted as a tornado diagram including the 20 most significant impactors on the range of the ICER. For the deterministic sensitivity analyses and probabilistic sensitivity analysis, a synchronized $\pm 10 \%$ variation was assumed and based on the approximate variation of known distributions, if distributional data were not available.

The probabilistic sensitivity analysis was done using the Monte Carlo method (1000 simulations) to capture both patient heterogeneity at baseline and variability related to all model parameters (Table 1). A cost-effectiveness plane was used to demonstrate the joint outcomes of simulated costs and QALYs. The costeffectiveness acceptability frontier [64] characterized the decision-maker's uncertainty and optimal treatment as a function of WTP [35], and the EVPI characterizes the average (i) value of additional research or (ii) opportunity cost based on simulations where the selected treatment was not optimal on the basis of the NMB. Finally, the EVA was estimated as the surplus value (economic profit) by subtracting the value of additional research or opportunity loss (i.e., EVPI) from the expected monetary benefit (i.e., NMB minus EVPI) and presented as an EVA curve.

\section{RESULTS}

Table 4 presents the discounted deterministic and probabilistic base-case results. RIV + ASA had modeled deterministic ICERs of $€ 8031 /$ QALY or $€ 6834 / L Y G$. The primary outcome was below the WTP of $€ 25,254 / \mathrm{QALY}$, demonstrating the average cost-effectiveness of RIV + ASA. The Supplementary material includes the results of the secondary and tertiary outcomes (See Table S2 in the electronic supplementary material for details), which concur with the primary outcome.

Among the cost drivers, medical care had the highest impact on the discounted total lifetime costs for both the intervention and comparator (49\% and $64 \%$ of total costs for RIV + ASA and ASA, respectively), followed by nonacute events (18\% and $27 \%)$, drug ( $26 \%$ and $1 \%)$, acute event 
Table 4 Deterministic and probabilistic discounted outcomes per patient

\begin{tabular}{|c|c|c|c|}
\hline Deterministic $^{\mathrm{a}}$ & RIV + ASA & ASA & Incremental \\
\hline Costs $(€)$ & 41,788 & 38,547 & 3241 \\
\hline Drugs & 11,929 & 403 & 11,525 \\
\hline Medical care & 19,846 & 24,411 & -4565 \\
\hline Acute nonfatal CVE & 1520 & 1985 & -465 \\
\hline Mortality & 1089 & 1332 & -243 \\
\hline Events & 7404 & 10,415 & -3011 \\
\hline QALYs & 10.333 & 9.929 & 0.404 \\
\hline ICER (€/QALY gained) & & & 8031 \\
\hline LYGs & 12.995 & 12.521 & 0.474 \\
\hline $\operatorname{ICER}(€ / L Y G)$ & & & 6834 \\
\hline Probabilistic $^{b}$ & QALYs & Costs & ICER \\
\hline Mean incremental & 0.420 & 1811 & 4313 \\
\hline SD incremental & 0.203 & 4796 & 12,045 \\
\hline Median incremental & 0.405 & 2899 & 11,304 \\
\hline Percentile, $2.5 \%$ & 0.107 & $-12,176$ & 597 \\
\hline Percentile, $97.5 \%$ & 0.899 & 7730 & 39,421 \\
\hline
\end{tabular}

$A S A$ acetylsalicylic acid $100 \mathrm{mg}$ once daily, $C V E$ cardiovascular event, ICER incremental cost-effectiveness ratio, $L Y$ life year, $L Y G$ life year gained, $Q A L Y$ quality-adjusted life year, $R I V$ rivaroxaban $2.5 \mathrm{mg}$ twice daily, $S D$ standard deviation, $V T E$ venous thromboembolism

${ }^{a}$ Deterministic, based on the mean values

b Probabilistic, based on the modeled distributions

(4\% and 5\%), and mortality costs (3\% and $3 \%)$ (Table 4). Overall $71 \%$ of patients experienced a CVE with RIV + ASA and $73 \%$ of patients with ASA; the most typical CVE was a nonfatal MI (35\% and $37 \%$ of all patients), followed by $\mathrm{MB}$ (38\% and 19\%), a nonfatal IS (13\% and $24 \%$ ), ALI (3\% and 6\%) and VTE (4\% and 5\%). Of all the modeled deaths, 28\% with RIV + ASA and $34 \%$ with ASA were due to CV reasons (see Table S2 in the electronic supplementary material).

In all scenario and deterministic sensitivity analyses for RIV + ASA, the results were below the WTP of $€ 25,254 / \mathrm{QALY}$. In the deterministic sensitivity analyses, the HRs of minor amputation, IS, major amputation, MI, and ICH had the biggest impact on the ICER (see Fig. S1 in the electronic supplementary material).

The simulation for the subgroups showed a lower than the base-case ICER for patients with PAD ( $€ 779 / \mathrm{QALY})$, patients with CCS and heart failure (€4933/QALY), or CCS and PAD (€6605/ QALY). Although still below the WTP of $€ 25,254 / \mathrm{QALY}$, the highest ICER overall was observed for patients with CCS and chronic kidney disease (€9290/QALY) or patients with CCS (€11,993/QALY).

The 15-year modeling scenario increased the average discounted ICER to $€ 18,192 / \mathrm{QALY}$ for RIV + ASA versus ASA. The undiscounted ICER was lower ( $€ 4708 / \mathrm{QALY}$, see Table $S 2$ in the electronic supplementary material) and the 5\% discounted ICER was higher $(€ 10,562 / \mathrm{QALY})$. 


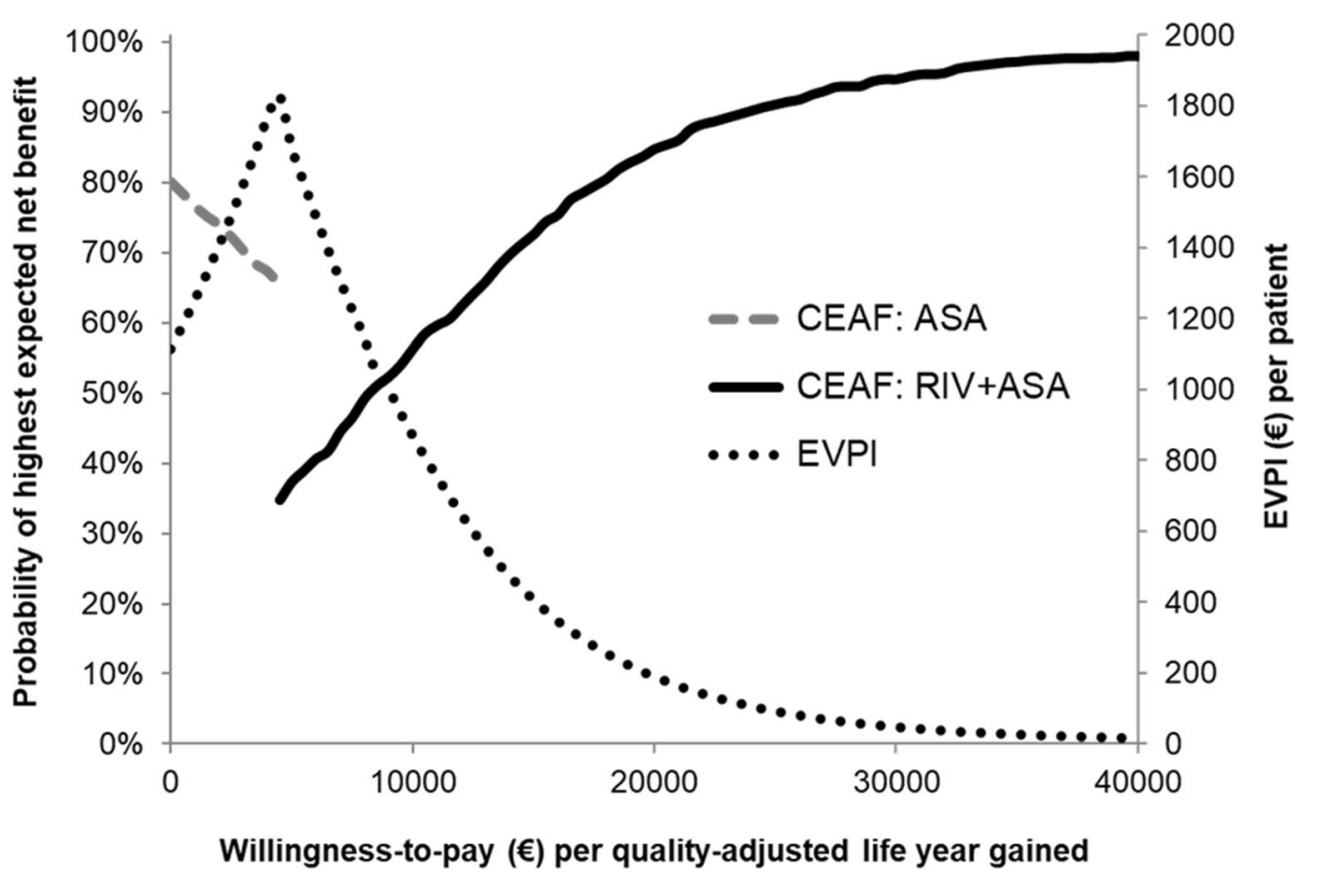

Fig. 2 Cost-effectiveness acceptability frontier (CEAF) and expected value of perfect information (EVPI) per patient for the discounted base-case results. ASA acetylsalicylic acid $100 \mathrm{mg}$ once daily, RIV rivaroxaban $2.5 \mathrm{mg}$ twice daily

Year 2020 as the base year resulted in a lower discounted average primary outcome of $€ 7221 /$ QALY, and the base year 2021 further decreased the ICER to $€ 6901 /$ QALY.

The scenario imputing zero probabilities decreased the average ICER to $€ 7930 / Q A L Y$. The discontinuation applied for the first 4 years resulted in modeled cost savings of $€ 478$ /patient (i.e., dominance of RIV + ASA), and constant discontinuation applied for the full model duration resulted in a low ICER of $€ 1007 /$ QALY. The ICER increased slightly when using the most recent CVE costs in the case of multiple CVEs (€8683/QALY). When the multiple main CVE costs were modeled to be additive, RIV + ASA dominated ASA with average cost savings of $€ 65 /$ patient. The ICER increased slightly when HRQoL was based on the most recent main CVE (€8056/QALY) or ATLAS (€8057/ QALY) and decreased more when multiplicative HRQoL for main CVEs ( $€ 7320 /$ QALY) or HRQoL based on the literature (€6986/QALY) was modeled.

The probabilistic modeled mean ICER of $€ 4313 /$ QALY was slightly lower in comparison with the deterministic primary outcome due to skewed distributions and patient heterogeneity. Thus, with the WTPs exceeding $€ 4313 /$ QALY, RIV + ASA saved modeled net costs based on the NMB. Starting from $€ 8224 /$ QALY, RIV + ASA had over $50 \%$ probability of cost-effectiveness, i.e., the combination was also potentially cost-effective. With the WTP of $€ 25,254 / \mathrm{QALY}$, RIV + ASA had 91\% probability of cost-effectiveness and dominated ASA in $20 \%$ of simulations (Fig. 2, see Fig. S2 in the electronic supplementary material).

The average modeled NMB was $€ 8791 / \mathrm{pa}$ tient when the QALY was valued with the WTP of $€ 25,254 / \mathrm{QALY}$, meaning that the corresponding average net savings were €8791/patient. As expected, the consequence of uncertainty was highest (EVPI $€ 1829 /$ patient) with the probabilistic base-case ICER $(€ 4313 /$ QALY) and was only $€ 88 /$ patient with the WTP of $€ 25,254 / \mathrm{QALY}$ (Fig. 2).

The average NMB exceeded the average EVPI from a WTP of $€ 7309 /$ QALY, i.e., with a WTP of at least $€ 7309 / \mathrm{QALY}$, total net savings exceeded the total opportunity costs or value of 
additional research information based on the modeled parameters, and a break-even was obtained (i.e., EVA was positive, see Fig. S3 in the electronic supplementary material). The EVA was $€ 8703 /$ patient with the WTP of $€ 25,254 / \mathrm{QALY}$.

\section{DISCUSSION}

We assessed the cost-effectiveness of antithrombotic treatment with RIV + ASA in patients with CCS or symptomatic PAD in Finland. Treatment with RIV + ASA is recommended for patients at high risk of ischemic events or diabetes and with a low risk of bleeding [30, 39].

The average ICER was $€ 8031 / \mathrm{QALY}$ for RIV + ASA versus ASA, which fell below the assumed WTP of $€ 25,254 /$ QALY and indicated that RIV + ASA is cost-effective in treating patients with CCS or symptomatic PAD. The highest costs resulted from medical care and nonacute events, with nonfatal MI being the most common CVE. The results with estimated costs fixed to year 2020 or 2021 value demonstrated that the primary outcome can even improve in the short term.

The incremental cost-effectiveness of treatments is determined by the difference in effectiveness as well as the difference in total costs. Thus, the cost-effectiveness of RIV + ASA versus ASA results from multiple factors such as the decrease in the incidences of events $(\mathrm{CV}$, other, mortality), the variation of costs and the impact to HRQoL.

In the probabilistic analysis, the ICER was only $€ 4313 / \mathrm{QALY}$ (EVPI $€ 1829 /$ patient) for RIV + ASA versus ASA. The NMB was high, the EVPI was low, and the EVA and probability of cost-effectiveness were high with the WTP of $€ 25,254 / \mathrm{QALY}: € 8791 /$ patient, €88/patient, $€ 8703 /$ patient, and $91 \%$, respectively, indicating that the estimated monetary gain (€8791/patient) was high compared with the estimated opportunity cost ( $€ 88 /$ patient). When the WTP exceeded $€ 7309 / \mathrm{QALY}$, the modeled average $\mathrm{NMB} /$ patient was higher than the modeled average EVPI/patient. Thus, from the
WTP of $€ 7310 / Q A L Y$, further research could be futile on the basis of the modeled parameters.

On the basis of the extensive scenario and deterministic sensitivity as well as NMB analyses, we can conclude that RIV + ASA was robustly cost-effective according to the WTP of $€ 25,254$ /QALY. In fact, RIV + ASA dominated ASA in several potential cases, such as scenarios in which multiple main CVE costs were modeled to be additive or QALYs were valued with the WTP of $€ 25,254 / \mathrm{QALY}$.

We considered the debate regarding the stable CAD term [31] and applied the CCS concept according to the ESC guidelines [30]. In comparison to the earlier stable CAD terminology, CCS describes the different clinical presentations of the disease and is coherent with acute coronary syndrome [30]. We used the PICOSTEPS approach to summarize and cover all the essential components of health economic evaluation according to their order of importance [34, 35]. PICOSTEPS has been applied successfully in multiple tasks, such as health economic evaluation review [33], costeffectiveness and cost-benefit assessments [34, 35, 65-70], health impact modeling [71], assessment of administration, travelling, and productivity costs [72], societal return of investment application [73] and reporting [74], and HTA of vaccines with multiple different perspectives [75].

All modeled comparisons are simplifications of the real-world phenomena that they examine. As a result, they typically include limitations and simplifying assumptions. The present study was no exception. First, the patient cohort characteristics and efficacy data were based on the COMPASS trial. On the basis of the published RWE, not all real-world patients with CCS or PAD meet the COMPASS trial inclusion criteria. However, $52.9 \%$ of patients with CAD or PAD enrolled in the REACH trial were COMPASS-eligible, with eligibility being the highest among individuals with PAD (68.4\%) [37], demonstrating the external validity of the current analysis. Interestingly, the REACH registry demonstrates that the rate of complications in real life is higher than what was observed in a clinical trial setting, suggesting that the benefit of adding RIV to ASA among 
patients with CCS or symptomatic PAD may be higher in real life.

The absolute effects of RIV + ASA can also be higher in real life, given the higher incidence of the composite outcome (CV death, MI, or stroke), all-cause mortality, CV death, and non$\mathrm{CV}$ death observed among COMPASS-eligible REACH patients in comparison with the ASA events observed in the COMPASS trial. Although the incidence of MI was similar, the incidence of nonfatal stroke was higher among the COMPASS-eligible REACH patients than among patients receiving ASA in the COMPASS trial [37]. Likewise, recent Polish RWE from Eastern Europe also demonstrated that incidence of the composite outcome, all-cause mortality, and MI was significantly higher in its COMPASS-like group, but other adverse CVEs, such as stroke or revascularization were similar [38]. Among the CVD population, specific characteristics (age greater than 65 years, diabetes, moderate renal failure, PAD, current smoker, heart failure, IS, and asymptomatic carotid stenosis) seem to dramatically increase ischemic risk but not bleeding risk, and should be considered in decision-making [76].

The European REACH subgroup did not differ from the average REACH registry cohort in terms of composite outcome, CV death, MI, or stroke among patients with symptomatic PAD [77]. Given that the European subgroup of the COMPASS trial had higher than average benefit from RIV in terms of the composite outcome [21], the present analysis could also underestimate the effects of adding RIV on top of ASA in the European setting.

Second, because no interaction between treatment and main event history on the risk of CVE was observed in the COMPASS trial, similar HRs were applied for both the first and second CVEs and regardless of subgroup. Moreover, HRs were modeled as constant over time, because no efficacy waning was observed in the COMPASS trial, although on the basis of the REACH registry $[36,77]$ risks may increase over time.

Third, in our base-case scenario RIV + ASA and ASA were modeled to be discontinued only when a patient died, owing to the lack of information for sequential modeling. This approach was conservative as the treatment effect takes into account the discontinuation based on the intention-to-treat data, and the use of RIV + ASA and ASA together with their cost was modeled for the lifetime of the patient. Thus, the potential sequential acute phase treatment with dual antiplatelet therapy (DAPT) after RIV + ASA or ASA in the case of second CVE was not considered.

Fourth, in the absence of an official Finnish WTP, an arbitrary WTP was assumed from the UK. Considering that The Finnish Medicines Agency [78] has proposed $€ 68,000 / \mathrm{QALY}$ to be approaching the maximum Finnish WTP for metastatic cancer, the WTP of $€ 25,254 / \mathrm{QALY}$ utilized here can be considered conservative. Another appealing alternative would be to use the plausible threshold of $£ 30,000$ from the UK ([51]; €37,881) or market valued gross-domestic product of $€ 42,076$ [58] multiplied by, e.g., one (mild disease), two (moderate disease), or three (severe disease), which are higher compared with the applied $€ 25,254 /$ QALY.

Finally, indirect costs were conservatively excluded. Significant differences have been observed among register-based and patient-reported indirect costs for other long-term diseases in Finland $[79,80]$. Although indirect costs have a pronounced impact on diseases affecting working-age individuals, they can also have major influences on the diseases of elderly, as well [62]. Overall, research indicates that indirect costs can have significant impacts [75]. Thus, society should be willing to invest in studies examining issues such as CCS or symptomatic PAD, to assess the true indirect costs and opportunity losses and find ways to limit their impact.

As discussed here, this modeled study had some overt limitations, such as the use of only one trial for efficacy, the lack of Finnish realworld effectiveness data, some expected differences with the real-life conditions, and exclusion of indirect costs. All these limitations arise from lack of data, which is common for new indications of interventions like CAD or PAD for RIV. Yet, we feel that this study is relevant for healthcare decision-makers when there was not enough Finnish real-world data for RIV + 
ASA in CAD or PAD available at the time of analysis.

\section{CONCLUSIONS}

On the basis of the modeling, adding RIV to ASA for patients with CCS or symptomatic PAD was robustly cost-effective. The subgroup analyses confirm that these results are valid among various subpopulations. Future studies should incorporate indirect costs, as well as caregiver perspectives and HRQoL to fully evaluate the societal value of using RIV + ASA in this population.

\section{ACKNOWLEDGEMENTS}

Funding. The study was financially supported by Bayer Oy, Espoo, Finland. The financial supporter (Bayer Oy, Espoo, Finland) participated in the identification, design, conduct, and reporting of the study. The study sponsor also funded Journal's Rapid Service and Open Access Fees.

Authorship. All named authors meet the International Committee of Medical Journal Editors (ICMJE) criteria for authorship for this article, take responsibility for the integrity of the work as a whole, and have given their approval for this version to be published.

Author's Contributions. Study: management (ES, OV), conceptualization (ES, OV), design (all); data: acquisition (ES, OV, AM), interpretation (all); analysis: design (ES, OV), implementation (ES), interpretation (all); manuscript: initial drafting (ES), critical revision (all), and final approval (all). The authors acknowledge Chameleon Communications International who provided limited editorial assistance in preparing the manuscript for submission (funded by Bayer).

Prior Presentation. Selected parts of the results were presented at the International Society for Pharmacoeconomics and Outcomes
Research ISPOR Europe 2019 Conference (CostEffectiveness of Coronary and Peripheral Artery Disease Treatments. Value Health 2019;22:S546).

Disclosures. Erkki Soini and Saku Väätäinen are employees of ESiOR Oy, Kuopio, Finland. Erkki Soini, is also a founding partner and director of ESiOR. ESiOR carries out studies, statistical analysis, consultancy, education, reporting, and health economic evaluations for several pharmaceutical, food industry, diagnostic, and device companies, hospitals, consultancies, academic institutions and projects, including the producers and marketers of CCS or PAD treatments. ESiOR received financial support for the study from Bayer Oy. Neither Erkki Soini nor Saku Väätäinen received any direct financial support as individuals and declare no personal conflicts of interests. Outi Virtanen is an employee of Bayer Oy. Bayer is the manufacturer and Bayer Oy is the marketer of rivaroxaban in Finland. OV declares no other potential conflicts of interest. Jean-Baptiste Briere is an employee of Bayer AG. Kevin Bowrin is an employee of Bayer Plc. Aurelie Millier is an employee of Creativ-Ceutical and declares no other potential conflicts of interest.

Compliance with Ethics Guidelines. This study was based on previously conducted studies and did not include any new studies with human participants or animals performed by any of the authors and was not registered with any clinical trial database.

Data Availability. Data sharing is not applicable as no new datasets were generated or analyzed during this study. No data are deposited in publicly available repositories or published alongside the paper as supplementary material.

Open Access. This article is licensed under a Creative Commons Attribution-NonCommercial 4.0 International License, which permits any non-commercial use, sharing, adaptation, distribution and reproduction in any medium or format, as long as you give appropriate credit to the original author(s) and 
the source, provide a link to the Creative Commons licence, and indicate if changes were made. The images or other third party material in this article are included in the article's Creative Commons licence, unless indicated otherwise in a credit line to the material. If material is not included in the article's Creative Commons licence and your intended use is not permitted by statutory regulation or exceeds the permitted use, you will need to obtain permission directly from the copyright holder. To view a copy of this licence, visit http:// creativecommons.org/licenses/by-nc/4.0/.

\section{REFERENCES}

1. Sanchis-Gomar F, Perez-Quilis C, Leischik R, Lucia A. Epidemiology of coronary heart disease and acute coronary syndrome. Ann Transl Med. 2016;4: 256.

2. Cervellin G, Lippi G. Of MIs and men-a historical perspective on the diagnostics of acute myocardial infarction. Semin Thromb Hemost. 2014;40: 535-43.

3. Alaraajojen tukkiva valtimotauti. Suomalaisen Lääkäriseuran Duodecimin ja Suomen Verisuonikirurgisen Yhdistyksen asettama työryhmä. The Finnish Medical Society Duodecim. 2010.

4. Koponen P, Borodulin K, Lundqvist A, Sääksjärvi K, Jääskeläinen T, Koskela T, Koskinen S. FinTerveystutkimuksen perustulokset 2019. Verkkojulkaisu. 2019. www.terveytemme.fi/finterveys. Accessed 29 Nov 2019.

5. Official Statistics of Finland (OSF): Deaths. Helsinki: Statistics Finland. 2019. https://www.stat.fi/til/ kuol/index_en.html. Accessed 11 Dec 2019.

6. Official Statistics of Finland (OSF): Causes of death. Helsinki: Statistics Finland. 2019. https://www.stat. fi/til/ksyyt/index_en.html. Accessed 11 Dec 2019.

7. Wickstrom JE, Virtanen J, Laivuori M, Jalkanen J, Venermo M, Hakovirta H. Data on association of ankle pressure and ankle brachial index of symptomatic and contralateral lower extremities with overall and cardiovascular mortality in patients with lower extremity peripheral artery disease. Data Brief. 2018;20:691-7.
8. Jousilahti P, Laatikainen T, Peltonen M, et al. Primary prevention and risk factor reduction in coronary heart disease mortality among working aged men and women in eastern Finland over 40 years: population based observational study. BMJ. 2016;352:i721.

9. Stenvall H, Tierala I, Rasanen P, Laine M, Sintonen $\mathrm{H}$, Roine RP. Long-term clinical outcomes, healthrelated quality of life, and costs in different treatment modalities of stable coronary artery disease. Eur Heart J Qual Care Clin Outcomes. 2017;3: 74-82.

10. Saarni SI, Harkanen T, Sintonen H, et al. The impact of 29 chronic conditions on health-related quality of life: a general population survey in Finland using 15D and EQ-5D. Qual Life Res. 2006;15:1403-14.

11. Miettola E, Koskela TH, Soini E, Ryynanen OP. Mikä on terveyskeskuspotilaiden elämänlaatu? Yleislääkäri. 2017;32:21-6.

12. Korhonen PE, Kautiainen H, Mantyselka P. Screening for cardiovascular risk factors and self-rated health in a community setting: a cross-sectional study in Finland. Br J Gen Pract. 2014;64:e611-615.

13. Meretoja A. PERFECT-STROKE. PERFormance, effectiveness, and costs of treatment episodes in stroke [thesis]. Department of Neurology. Helsinki University Central Hospital. 2011.

14. Häkkinen U, Idänpään-Heikkilä U, Keskimäki I, Klaukka T, Peltola M, Rauhala A, Rosenqvist G. PERFECT Sydäninfarkti Sydäninfarktin hoito, kustannukset ja vaikuttavuus. 2017.

15. Hallinen T, Soini E, Asseburg C, Suominen R, Laine $\mathrm{H}$. Cost-effectiveness of insulin glargine compared to other long-acting basal insulins in the treatment of Finnish type 1 and type 2 diabetes patients based on individual studies. Dosis. 2012;28:145-64.

16. Hallinen T, Soini EJ, Linna M, Saarni SI. Cost-effectiveness of apixaban and warfarin in the prevention of thromboembolic complications among atrial fibrillation patients. Springerplus. 2016;5: 1354.

17. Heinonen J, Koskela TH, Soini E, Ryynanen OP. Primary-care-based episodes of care and their costs in a three-month follow-up in Finland. Scand J Prim Health Care. 2015;33:283-90.

18. Kettunen R. Sepelvaltimotauti. Lääkärikirja duodecim. 2018. Accessed 29 Nov 2019.

19. Stabiili sepelvaltimotauti. Suomalaisen Lääkäriseuran Duodecimin ja Suomen Verisuonikirurgisen Yhdistyksen asettama työryhmä, 13.4.2015. The Finnish Medical Society Duodecim. 2015. 
20. Fox KAA, Eikelboom JW, Shestakovska O, Connolly SJ, Metsarinne KP, Yusuf S. Rivaroxaban plus aspirin in patients with vascular disease and renal dysfunction: from the COMPASS trial. J Am Coll Cardiol. 2019;73:2243-50.

21. Eikelboom JW, Connolly SJ, Bosch J, et al. Rivaroxaban with or without aspirin in stable cardiovascular disease. N Engl J Med. 2017;377: 1319-30.

22. Anand SS, Bosch J, Eikelboom JW, et al. Rivaroxaban with or without aspirin in patients with stable peripheral or carotid artery disease: an international, randomised, double-blind, placebocontrolled trial. Lancet. 2018;391:219-29.

23. Anand SS, Caron F, Eikelboom JW, et al. Major adverse limb events and mortality in patients with peripheral artery disease: the COMPASS trial. J Am Coll Cardiol. 2018;71:2306-15.

24. Connolly SJ, Eikelboom JW, Bosch J, et al. Rivaroxaban with or without aspirin in patients with stable coronary artery disease: an international, randomised, double-blind, placebo-controlled trial. Lancet. 2018;391:205-18.

25. Bhagirath VC, Eikelboom JW, Anand SS. Low-dose rivaroxaban plus aspirin for the prevention of cardiovascular events: an evaluation of COMPASS. Future Cardiol. 2018;14:443-53.

26. Kruger PC, Anand SS, de Vries TAC, Eikelboom JW. Patients with peripheral artery disease in the COMPASS trial. Eur J Vasc Endovasc Surg. 2018;56: 772-3.

27. Sharma M, Hart RG, Connolly SJ, et al. Stroke outcomes in the Cardiovascular OutcoMes for People using Anticoagulation StrategieS (COMPASS) Trial. Circulation. 2019;139:1134-45.

28. Lamy A, Eikelboom J, Sheth T, et al. Rivaroxaban, aspirin, or both to prevent early coronary bypass graft occlusion: the COMPASS-CABG study. J Am Coll Cardiol. 2019;73:121-30.

29. Branch KR, Probstfield JL, Eikelboom JW, et al. Rivaroxaban with or without aspirin in patients with heart failure and chronic coronary or peripheral artery disease: the COMPASS trial. Circulation. 2019;140:529-37.

30. Knuuti J, Wijns W, Saraste A, et al. 2019 ESC guidelines for the diagnosis and management of chronic coronary syndromes. Eur Heart J. 2020;41: 407-77.

31. Fox KAA, Metra M, Morais J, Atar D. The myth of 'stable' coronary artery disease. Nat Rev Cardiol. 2020;17:9-21.
32. Hila. Terveystaloudellisen selvityksen laatiminen lääkevalmisteen korvattavuus- ja tukkuhintahakemukseen. 2019.

33. Soini E. Biologisten lääkkeiden kustannusvaikuttavuus nivelpsoriaasin hoidossa. Helsinki: Suomalainen Lääkäriseura Duodecim. 2017. https://www. kaypahoito.fi/nix02465. Accessed 29 Nov 2019.

34. Soini E, Joutseno J, Sumelahti ML. Cost-utility of first-line disease-modifying treatments for relapsing-remitting multiple sclerosis. Clin Ther. 2017;39(537-557):e510.

35. Soini E, Riekkinen $\mathrm{O}$, Kroger $\mathrm{H}$, Mankinen $\mathrm{P}$, Hallinen T, Karjalainen JP. Cost-effectiveness of pulse-echo ultrasonometry in osteoporosis management. Clinicoecon Outcomes Res. 2018;10: 279-92.

36. Wilson PW, D'Agostino R Sr, Bhatt DL, et al. An international model to predict recurrent cardiovascular disease. Am J Med. 2012;125:695-703.

37. Darmon A, Bhatt DL, Elbez Y, et al. External applicability of the COMPASS trial: an analysis of the Reduction of Atherothrombosis for Continued Health (REACH) registry. Eur Heart J. 2018;39: 750-757a.

38. Desperak P, Hudzik B, Gasior M. Assessment of patients with coronary artery disease who may benefit from the use of rivaroxaban in the real world: implementation of the COMPASS trial criteria in the TERCET registry population. Pol Arch Intern Med. 2019;129:460-8.

39. Cosentino F, Grant PJ, Aboyans V, et al. 2019 ESC guidelines on diabetes, pre-diabetes, and cardiovascular diseases developed in collaboration with the EASD. Eur Heart J. 2019;41:255-32323.

40. Porela P. Stabiili sepelvaltimotauti. Duodecim. 2018;134:333-40.

41. Mancini GB, Gosselin G, Chow B, et al. Canadian Cardiovascular Society guidelines for the diagnosis and management of stable ischemic heart disease. Can J Cardiol. 2014;30:837-49.

42. Montalescot G, Sechtem U, Achenbach S, et al. 2013 ESC guidelines on the management of stable coronary artery disease: the Task Force on the management of stable coronary artery disease of the European Society of Cardiology. Eur Heart J. 2013;34:2949-3003.

43. Scottish Intercollegiate Guidelines Network (SIGN). Antithrombotics: indications and management. $2013 . \quad$ https://www.sign.ac.uk/sign-129antithrombotics-indications-and-management. html. Accessed 29 Nov 2019. 
44. Haute Autorité de Santé Bon usage des agents antiplaquettaires. Argumentaire. 2012. https:// www.ansm.sante.fr/var/ansm_site/storage/original/ application/e7a6fa9454e762c375beb2567332a903. pdf. Accessed 11 Dec 2019.

45. Haute Autorité de Santé Bon usage des agents antiplaquettaires. Recommandations. 2012. https:// ansm.sante.fr/var/ansm_site/storage/original/ application/31f541bfa5cbe1460f1a25ce11ba6550. pdf. Accessed 11 Dec 2019.

46. National Institute for Health and Care Excellence. Cilostazol, naftidrofuryl oxalate, pentoxifylline and inositol nicotinate for the treatment of intermittent claudication in people with peripheral arterial disease. Technology appraisal guidance TA223. 2011. https://www.nice.org.uk/guidance/TA223. Accessed 11 Dec 2019.

47. National Institutes of Health. Stable angina: management. 2011. https://www.nice.org.uk/guidance/ cg126/resources/stable-angina-management-pdf35109453262021 . Accessed 22 Jan 2019.

48. Abramson BL, Huckell V, Canadian Cardiovascular Society 2005 peripheral artery disease consensus document. 2005. https://ccs.ca/images/Guidelines/ Guidelines_POS_Library/PAD_CC_2005.pdf. Accessed 22 Jan 2019.

49. National Institute for Health and Care Excellence. Rivaroxaban for preventing atherothrombotic events in people with coronary or peripheral artery disease. Technology appraisal guidance [TA607]. 2019. https://www.nice.org.uk/guidance/ta607. Accessed 11 Dec 2019.

50. Fimea. Fimean suositus lääkkeiden hoidollisen ja taloudellisen arvon arvioinnista. 2012. https:// www.julkari.fi/handle/10024/130844. Accessed 11 Dec 2019.

51. National Institute for Health and Care Excellence. Guide to the methods of technology appraisal 2013. Process and methods [PMG9]. 2013. https://www. nice.org.uk/article/PMG9/chapter/Foreword. Accessed 11 Dec 2019.

52. Drummond M, Sculpher MJ, Torrance GW, O'Brien BJ, Stoddart GL. Methods for the economic evaluation of health care programmes. Oxford: Oxford University Press; 2005.

53. Brouwer WR, Koopmanschap FM. Costing in economic evaluations. In: Drummond MMA, editor. Economic evaluation in health care: merging theory with practice. Oxford: Oxford University Press; 2001. p. 68-93.

54. Torrance GW, Siegel JE, Luce BR. Framing and designing the cost-effectiveness analysis. In: Gold
MR, Siegel JE, Russell LB, Weinstein MC, editors. Cost-effectiveness in health and medicine. Oxford: Oxford University Press; 1996. p. 55-80.

55. Mandelblatt J, Fryback DG. Assessing the effectiveness of health interventions. In: Gold MR, editor. Cost-effectiveness in health and medicine. Oxford: Oxford University Press; 1996.

56. Bavry AA, Elgendy IY, Elbez Y, et al. Aspirin and the risk of cardiovascular events in atherosclerosis patients with and without prior ischemic events. Clin Cardiol. 2017;40:732-9.

57. Official Statistics of Finland (OSF): Price index of public expenditure. Helsinki: Statistics Finland. 2019. https://www.stat.fi/til/jmhi/index_en.html. Accessed 14 Jun 2019.

58. Official Statistics of Finland (OSF): Annual national accounts. Helsinki: Statistics Finland. 2019. https:// www.stat.fi/til/vtp/index_en.html. Accessed 11 Dec 2019.

59. Heeg BM, Peters RJ, Botteman M, van Hout BA. Long-term clopidogrel therapy in patients receiving percutaneous coronary intervention. Pharmacoeconomics. 2007;25:769-82.

60. Kapiainen S, Väisänen A, Haula T. Terveyden-ja sosiaalihuollon yksikkökustannukset Suomessa vuonna 2011. Tampere: Juvenes Print-Suomen Yliopistopaino Oy. 2014.

61. Soini E, Kukkonen J, Myllykangas M, Ryynanen OP. Contingent valuation of eight new treatments: what is the clinician's and politician's willingness to pay? Open Complement Med J. 2012;4:1-11.

62. Soini EJ, Hallinen T, Sokka AL, Saarinen K. Costutility of first-line actinic keratosis treatments in Finland. Adv Ther. 2015;32:455-76.

63. OECD. Prices and purchasing power parities. 2019. https://www.oecd.org/sdd/prices-ppp/. Accessed 29 Nov 2019.

64. Barton GR, Briggs AH, Fenwick EA. Optimal costeffectiveness decisions: the role of the cost-effectiveness acceptability curve (CEAC), the cost-effectiveness acceptability frontier (CEAF), and the expected value of perfection information (EVPI). Value Health. 2008;11:886-97.

65. Soini E, Väätäinen S, Arvonen S. Predicted costbenefit of Virtual Hospital 2.0 in terms of health care capacity freed: towards potential economic efficiency with digitalization and customer-responsive secondary care services. WHO International Healthy Cities Conference. 2018. 
66. Väätäinen S, Soini E, Arvonen S. Digitalization and customer-responsive secondary care services potentially free health care capacity: predicted monetary benefits of Virtual Hospital 2.0. Value Health. 2018;21:S151.

67. Väätäinen S, Soini E, Arvonen S, Suojanen L, Pietiläinen $\mathrm{KH}$. Potential direct secondary care cost benefits of HealthyWeightHub-Virtual Hospital 2. 0 digital lifestyle intervention. Finnish $\mathrm{J}$ eHealth eWalfare. 2019;11:342-56.

68. Väätäinen S, Soini E, Peltola J, Charokopou M, Taiha M, Kälviäinen R. Economic value of adjunctive brivaracetam treatment strategy for focal onset seizures in Finland. Adv Ther. 2020;37:477-500.

69. Mankinen P, Lundström T, Soini E, et al. Cost assessment modelling of treatments for highly active relapsing multiple sclerosis. Adv Ther. 2020;37:800-18.

70. Väätäinen S, Soini E, Liljeroos L, Soilu-Hänninen M. Alemtuzumab is a budget-saving alternative to fingolimod and natalizumab in the treatment of highly active relapsing-remitting multiple sclerosis. Dosis. 2020;36:36-59.

71. Soini E, Hallinen T, Laine J. Health impact modelling (HIM): concept, approach and real-world data needs for the estimation of potential effectiveness provided by a pharma company portfolio. Value Health. 2017;21:S88.

72. Mankinen P, Vihervaara V, Torvinen S, Martikainen J, Soini E. Costs of administration, travelling, and productivity losses associated with hospital administration of multiple myeloma drugs in Finland. J Med Econ. 2019;22:328-35.

73. ESiOR. StopDia-investointilaskuri tyypin 2 diabeteksen ehkäisyn terveystaloudellisten vaikutusten arviointiin. 2019. https:/esior.io/ stopdialaskuri1/. Accessed 22 Sep 2019.

74. ESiOR. Kohti terveyttä edistävää Suomea 2030. StopDia-investointilaskurin tulosraportti. 2019.

75. Mankinen P, Soini E, Linna M, Turunen J, Martikainen J, Laine J. Näkökulma vaikuttaa terveysteknologioiden taloudellisen arvioinnin tuloksiinesimerkkinä iäkkäiden pneumokokkirokottaminen. Dosis. 2019;35:118-35.

76. Darmon A, Sorbets E, Ducrocq G, et al. Association of multiple enrichment criteria with ischemic and bleeding risks among COMPASS-eligible patients. J Am Coll Cardiol. 2019;73:3281-91.

77. Abtan J, Bhatt DL, Elbez Y, et al. Geographic variation and risk factors for systemic and limb ischemic events in patients with symptomatic peripheral artery disease: Insights from the REACH registry. Clin Cardiol. 2017;40:710-8.

78. Fimea. Lääkkeiden HTA-neuvottelukunnan kokous 3/2014. 2014. https://www.fimea.fi/documents/ 160140/1156014/27681_141020_HTAneuvottelukunta_Muistio_141104_JK_TO_VK.pdf/ c031657c-c955-423d-870b-3c90e1455c0e. Accessed 22 Sep 2019.

79. ESiOR. Tekemätöntä työtä, näkymättömiä kustannuksia-Selvitys tulehduksellisia suolistosairauksia ja reumasairauksia sairastavien työ- ja toimintakyvystä sekä niiden menetyksestä aiheutuvista kustannuksista. 2017. https://crohnjacolitis.fi/wpcontent/uploads/2017/10/Tekemätöntä-työtänäkymättömiä-kustannuksia-selvitys.pdf. Accessed 22 Sep 2019.

80. Soini E. Productivity losses, 2nd Nordic conference on Real World Data. Helsinki. 2017. 